\title{
Exploring Two Decades of Research in Community Resilience: A Content Analysis Across the International Literature
}

\section{Yangyang Fan (D) \\ Xiaojun Lyu}

Department of Public Administration, School of International and Public Affairs, Shanghai Jiao Tong University, Shanghai, People's Republic of China
Correspondence: Xiaojun Lyu

Email xjlv@sjtu.edu.cn
Introduction: Community resilience (CR) has gradually become a hot topic in uncertain times, especially in the last five years. The current study presents a systematic review based on content analysis to present a knowledge graph of CR research over the last 20 years.

Methods: We use an approach of Leximancer to conduct the content analysis to explore the intellectual foundations, research context, topics, and methods of CR literature based on 583 published studies.

Results: The results show that framework research of $\mathrm{CR}$ is a hot topic throughout the last 20 years. In the first stage (from 2001 to 2015), CR connected with the themes of "framework, disaster, change, and model". Comparatively, in the second stage (from 2016 to 2020), the themes of "social capital, capacity, and framework" are more salient connecting with CR. Additionally, the study detected that the key issues varied across countries. Specifically, research in the US focused on the social support dynamic, while in Australia, recovery from the disaster was the predominant theme. Furthermore, in the UK, studies mostly explore resilience issues in the background related to flooding.

Discussion: Our findings provide a comprehensive picture of $\mathrm{CR}$ research covering the last 20 years and put forward thoughts and recommendations for future resilience studies considering 1) obstacles within daily life, 2) resilience set within organizational perspectives, and 3) cultural context.

Keywords: community resilience, content analysis, text mining, cross-country comparison

\section{Introduction}

Over the last several decades, resilience research has gradually become a hot topic in many disciplines, including developmental psychology, ${ }^{1,2}$ mental health, ${ }^{3}$ management, ${ }^{4}$ and environmental research. ${ }^{5}$ Over the last 20 years, resilience has developed from the individual level to expand into the domains of community, city, and environment. 6,7

Given the increasing interest in community resilience (CR) in recent years, a systematic review of $\mathrm{CR}$ is essential, and provides an empirical guideline for future research. ${ }^{8,9}$ To our knowledge, there are no systematic reviews on the topic of CR based on content analysis of the literature. Norris et al drew upon the literature in several disciplines and presented CR as a metaphor, theory, set of capacities, and strategy for disaster readiness, but without systematic review for cross-country comparison. ${ }^{9}$ Kirmayer et al discussed the concepts, models, metaphors, and measures of $\mathrm{CR}$ within the context of Aboriginal communities but 
neglected to use empirical methods of a systematic review. ${ }^{3}$ Follow-up studies focused on exploring CR models and dimensions based on specific countries or communities under different kinds of natural disasters or risk events. ${ }^{10,11}$ Recently, Koliou et al conducted a literature review of $\mathrm{CR}$ research mainly focusing on natural hazards without a systematic literature review process. ${ }^{12}$ As the field has grown rapidly in recent years, it is essential to conduct a systematic review of CR to uncover the knowledge graph based on content analysis.

This research presents a comprehensive review of CR literature to explore the intellectual foundations, research context, topics, and methodological approach of the literature on CR. In this study, we want to reply to these questions:

1. What is the key focus of the CR research in the past 20 years?

2. What are the differences between community resilience research in different countries?

3. How will relevant research be better carried out in the future about CR?

The paper is organized as follows: First we will review Resilience and CR as illustrated in the previous literature spanning diverse disciplines. Next, we conducted a content analysis to respond to the above questions with the help of Leximancer. We conclude with a discussion of the theoretical framework for $\mathrm{CR}$ and share some ideas about the future direction for $\mathrm{CR}$ research. This article provides a panoramic description of interdisciplinary CR research and makes a novel contribution to the resilience studies at the community level, but through an international comparative lens.

\section{A Review of Resilience}

Resilience is best explained by a famous aphorism: "What does not destroy me, makes me stronger" (p.201), which is expressed by Nietzsche's Twilight of the Idols. ${ }^{13}$ Also, it is vividly described by Charles Darwin's Theory of Evolution, "It's not the strongest species that survive, nor the most intelligent, but the most responsive to change" (p26). ${ }^{14}$ Resilience is most commonly viewed as a positive adaptation in the context of significant adversity. ${ }^{3}$ As an important concept both in natural science and social science, the research about resilience has grown rapidly in many subjects (developmental psychology, management, health, environment) from the micro-level to the macro-level. Resilience is not a process that is isolated from other social contexts or systems. On the contrary, it is a complicated process that is intertwined with resources and multiple influences of internal and external factors. ${ }^{7}$

Although the concept of resilience in the previous research has something in common, it still has different meanings across-subjects. Resilience in environmental management (ecological systems) literature has a long history, which defines resilience as the ecosystem's capacity for absorbing and recovering under the context of external shocks. Environmental corporate social responsibility, environmental well-being, resilient infrastructure, social capital and social learning theory were strengthened as theoretical backgrounds in environmental management research. ${ }^{15}$ From the perspective of social science, Keck and Sakdapolrak described resilience as the capacities or abilities of social entities to absorb, cope with and adjust to various social threats and environmental disasters. ${ }^{16}$ Additionally, in psychology and mental health, resilience seems like a feature of individuals facing adversity who have positive developmental outcomes. ${ }^{3}$ Social resilience theory and empowerment theory were strengthened as theoretical backgrounds in psychology research. ${ }^{7,8}$ To some extent, the ideas from ecosystems and physiological systems may be used to understand sociological or psychological processes. ${ }^{3}$ Overall, the common understanding of resilience is that it relates to the ability to provide positive outcomes when facing external adversity.

Resilience at the different levels has developed in different stages. The individual-level research of resilience has significantly attracted the interest of mental health and developmental psychology, while ecosystem resilience has always been a research hotspot around the world. ${ }^{1,17}$ However, empirical research on CR is still in the infancy stage. From a community systems perspective, the community is like a bridge connecting micro-level (individuals and family) and macro-level (social system or ecology). If a resilient community can promote the development of the whole social ecosystem, then it is essential to make clear the research progress of $\mathrm{CR}$ to continue to help social systems survive through healthy individuals and families.

\section{A Review of Community Resilience}

Community refers to a social unit (a group of people living in the same place) with commonality, such as values, norms, customs, religion, or identity. ${ }^{18}$ Resilience at the community level has gained more attention in the past 20 years. The community's resilience is not defined by the 
sum of individual member resilience. ${ }^{19-21}$ Resilience at the community level is interrelated with resilience at the individual, household, and organizational levels. ${ }^{7}$ Resilience in the community system itself involves the adjustments and adoption of organizations, families, and individuals within the community, and it also interacts with the whole community. ${ }^{3}$ Additionally, resilience at the community level has attracted much interest in the fields of psychology, public administration, crisis management, and environmental science.

For the definition of CR, there is much research that provides a clear description of it from different perspectives. From a general aspect, the Presidential Policy Directive defines $\mathrm{CR}$ as the ability to prepare and adapt to changing conditions, able to withstand disturbances and quickly recover from them. ${ }^{22}$ From a theoretical perspective, Brown and Kulig defined CR as the community members' ability to engage in community affairs or projects despite structures and events that obstruct such projects. $^{21}$ From a social sustainability perspective, Magis defined CR as the ability of community members to try to thrive in the development and engagement of community resources under an uncertain, unpredictable, changing, and surprising context. ${ }^{23}$ From the perspective of the health system, Bhandari and Alonge defined CR as a process of linking a set of network adaptability (resources with dynamic attributes) at the individual or community level with the function of the health system at the community level after a health shock and the positive trajectory of adaptation. ${ }^{24}$ Based on diverse perspectives, we can conclude that $\mathrm{CR}$ is a proactive process, not a passive response. ${ }^{25,26}$

For the framework and dimension of CR, many efforts have been done in the previous research. Norris et al explored a framework from four adaptive capacities: community competence, social capital, information and communication, and economic development. ${ }^{9}$ Based on the literature review and focus group discussion, Magis developed Community Resilience Self-Assessment from eight dimensions: community resources, resources development, resources engagement, impact, equity, strategic action, collective action, and active agents. ${ }^{23}$ From both the social-ecological systems and psychology of development and mental health perspectives, Berkes and Ross explored an integrated approach for future research of CR. ${ }^{7}$ Based on the previous CART (Communities Advancing Resilience Toolkit) survey instrument, Pfefferbaum et al developed a five-factor model of CR: connection and caring, resources, transformative potential, disaster management, and information and communication. ${ }^{27}$ Although various $\mathrm{CR}$ frameworks or dimensions were explored in the previous research, CR itself is difficult to be measured directly.

However, there is still a long way to go for the CR research. The current theoretical models of CR have only illustrated a series of factors promoting the resilience of the community rather than the models of itself. $^{28}$ Relatively few instruments are available to build and conducive to measure $\mathrm{CR}$, as some researchers maintain that measurements of $\mathrm{CR}$ should be based on specific communities and scenarios. ${ }^{3}$ More importantly, much of the past research about focused on exploring the measurement and its framework or dimensions, with few studies exploring the consequence of $\mathrm{CR}^{27,29}$ These puzzles can only be carried out on the basis of a systematic review of the existing literature. By quantifying and then theorizing a unified academic framework, we can better promote the development of CR to allow for meaningful research that will advance practice and theory.

\section{Methods}

\section{Selection of the CR-Based Literature}

This study included articles related to CR that were published from January 2001 to September 2020 from Web of Science (WoS) and Scopus, as both databases can provide advanced search functions to allow us to restrict the search terms. Due to the diversity of research on CR, we only included papers that put community resilience at the core of the research. We restricted the search limitations as follows: (1) "community resilience" or "resilient community" was included in the title; (2) only English articles were included; (3) journal articles specifically included CR as a concept; (4) CR was the main theme or a dominant focus throughout the abstract. There are 515 research articles in the Scopus database and 436 studies in the WOS database. After deleting the duplicate articles from both databases, 764 articles were downloaded into the Endnote software with the abstract included for each article. Based on the title and abstract, 127 articles and 54 articles were excluded in the first and second round of exclusion separately, there are 583 articles included at the final stage (Figure 1). Then, we imported the title and abstract of each article into an Excel document to analyze using Leximancer. 


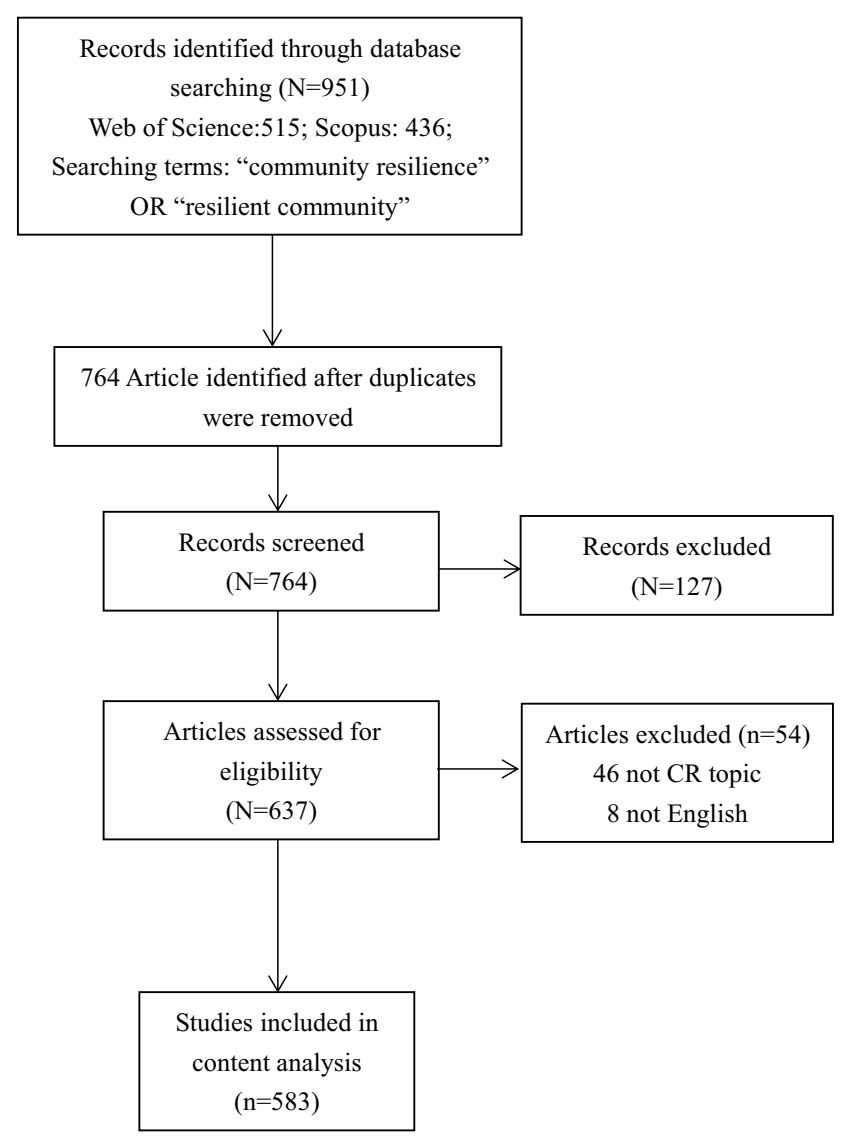

Figure I Systematic literature review process.

\section{Content Analysis in Leximancer}

Leximancer (ver. 4.5) is a textual data analysis software for text mining and artificial learning. ${ }^{30}$ Leximancer can identify families of terms based on word frequency and co-occurrence data in the text. It is not only a simple text analysis software but also a way to provide novel quantitative text information and realize visualization. As a software system for conceptual analysis of text data in a language-independent manner, it automatically analyzes text documents to identify high-level concepts in text documents and provide required key ideas and actionable insights through a powerful interactive visualization and data export system. Compared with the standard content analysis, Leximancer can automatically identify the main concepts among a set of texts and coding those concepts in a visual map.

Leximancer treated the high-frequency words in the texts as concepts. The facility for interactive conceptmapping in Leximancer assisted our researchers in understanding the textual dataset by providing an overview of the conceptual structure. ${ }^{31}$ The software clustered the concepts based on connections, and similar concepts or high correlation of words were settled together in close proximity. Additionally, Leximancer grouped concept clusters by theme circles, and each circle was named based on the most prominent dot in that theme cluster (researchers renamed themes according to the concepts in that theme circle). Based on the cluster map and the rankordered concept lists, we explored the relationships of those concepts to better understand the semantic structure of the data.

In this study, there were enough studies (583 articles) on CR to meet the conditions for text analysis based on Leximancer. To better understand the development of this topic, we divided the dataset into two stages: the first stage is from 2001 to 2015 (initial 15 years, less than 50 articles in each year), and the second stage is from 2016 to 2020 (recent five years) with more than 50 articles in each year. The analysis of data from the past five years (2016-2020) will help us better understand developmental trends of CR. Additionally, we analyzed the text based on the country mentioned in the titles and abstracts, along with the first author's country.

\section{Results}

Before analyzing the data, the non-lexical and weak semantic information was excluded according to the standard exclusion words in Leximancer (such as the words "of", "and", and "not"). The general terms that were applied frequently in the abstracts were also removed because of the meaninglessness to the concept maps (such as "article", "paper", "during", "study", and "research"). Additionally, the singular and plural of words were merged into plural forms (for example: "community" and 'communities', "disaster" and "disasters"). Additionally, to keep the completeness of the concept map, we set the visible concepts into $100 \%$ by showing all the concepts in the map, and the theme size is set to $50 \%$. Based on the cluster map (the size and connection between concepts) and the rank-ordered concept lists, we explored the relationships of those concepts and better understood the semantic structure of the data.

\section{Text Mining Analysis Among All Data}

An initial overall (2001-2020) analysis was conducted automatically with titles and abstracts of all 583 articles. Eight themes (Community, resilience, disaster, social capital, impact, framework, rural, effect) including 56 concepts were shown in the overall map. Based on the analysis, we 
numbered the themes in rank order from 1 to 8 , with the "community" and "resilience", the focusing topic in this article, ranked top two, and "effect", the least prominent theme, ranked 8 . It should be noted that the size of the theme decided the prominence of the ranking theme: the larger the dot, the more prominent the theme.

Figure 2 shows the maps of concepts and themes from the overall dataset. From this $3 \mathrm{D}$ diagram, we can explore the connection and relationship between the 56 concepts. As can be seen in this overall map, social capital (ranked 4) is the most central concept, which means it is a hot topic that is related to the research about $\mathrm{CR}$. When we click the concept of social or capital on the map in Leximancer, it shows that almost all concepts are connected with these terms. We also know that during the last 20 years, CR research has been mainly connected with disaster (ranked 3). In these 583 articles, the theme hit 1030 times about the concept of disaster, which means resilience research at the community level is mostly under the condition of disaster.

Figure 2 also shows the main topic of CR in the last 20 years. The themes of "impact" (ranked 5), "framework" (ranked 6), and "effect" (ranked 8) clearly show the main

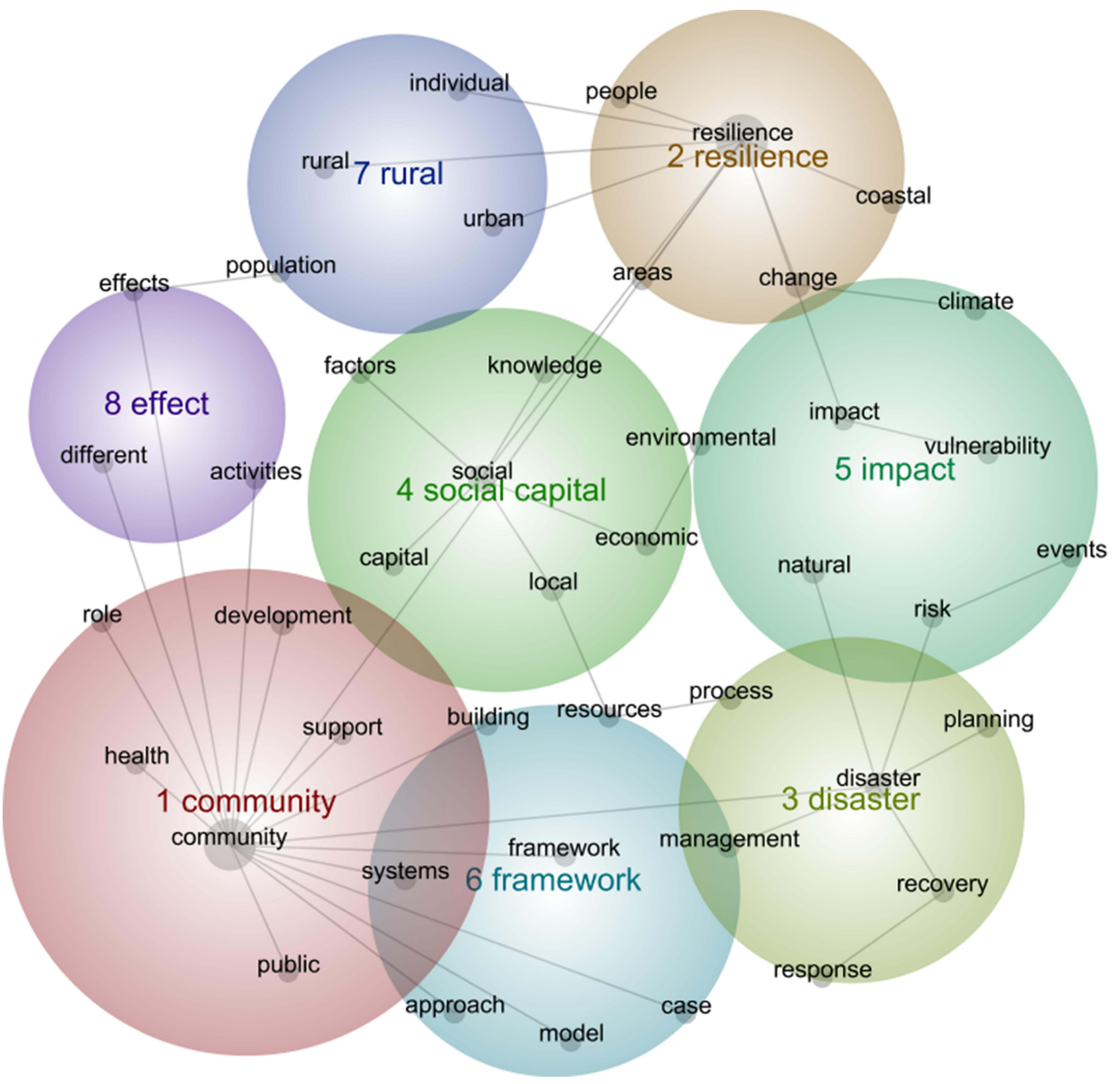

Figure 2 Overall map in Leximancer ( $N=583$ articles published between $200 \mathrm{I}$ and 2020). 
topic is about that the framework of $\mathrm{CR}$ and the impact and effect. Additionally, the concept of "framework" has to be counted 218 times in those 583 articles' title and abstract, with "impact" and effect were counted 211 and 109, respectively. At last, based on this map, after reading the sentences about the concepts in the theme of "rural", it is clear to know that research in CR is mostly using the qualitative method under the event or risk. The theme of rural (ranked 7) including four concepts, which are rural (120 hit times), urban (112 hit times), individual (106 hit times), and population (69 hit times).

Based on the content analysis in overall (2001-2020) database, we explored the intellectual foundations, research context, topics, and methods of CR literature. Figure 3 summarizes CR in the current literature.

\section{Text Mining Analysis Between 200I to 2015 Years}

After the pre-processing on the grounded analysis by Leximancer, we then run the content analysis based on the articles published in the initial 15 years. As shown in Figure 4, 6 themes (community, resilience, framework, disaster, change, and model) including 38 concepts were shown in the map, which illustrate the concept model and framework about the $\mathrm{CR}$ in the context of disaster and change. As we can see in Figure 4, community and resilience were still the most prominent, followed by themes of the framework. Additionally, the theme of "framework" is the most central concept, and it is connected with all the other 37 concepts in the map, which means it is a crucial topic that related to the research about CR between 2001 and 2015. Compared with the initial overall (2001-2020) analysis, the themes of "change" and "model" appeared in the initial 15 years, with the concept of "change" appeared 77 times and "model" appeared 54 times.

\section{Text Mining Analysis Between 2016 to 2020 Years}

Figure 5 presents seven themes (order ranking) including 44 concepts for the past five years (2016-2020). The most prominent theme is resilience, with its most pivotal concept connected to "risk" and "impacts". Same as the first two maps, the community is the second most prominent theme, with its most key concept "community" connected to "support", "system", "process", "approach", "role", and "case" around it. The third most prominent (social capital) linked the theme of community and resilience, which means social capital is a critical element in the research about CR.

The next most prominent theme is "framework" (ranked 4), and it is also one of the most prominent themes in the overall analysis (ranked 6) and the map of initial 15 years (ranked 3), which means the framework research of

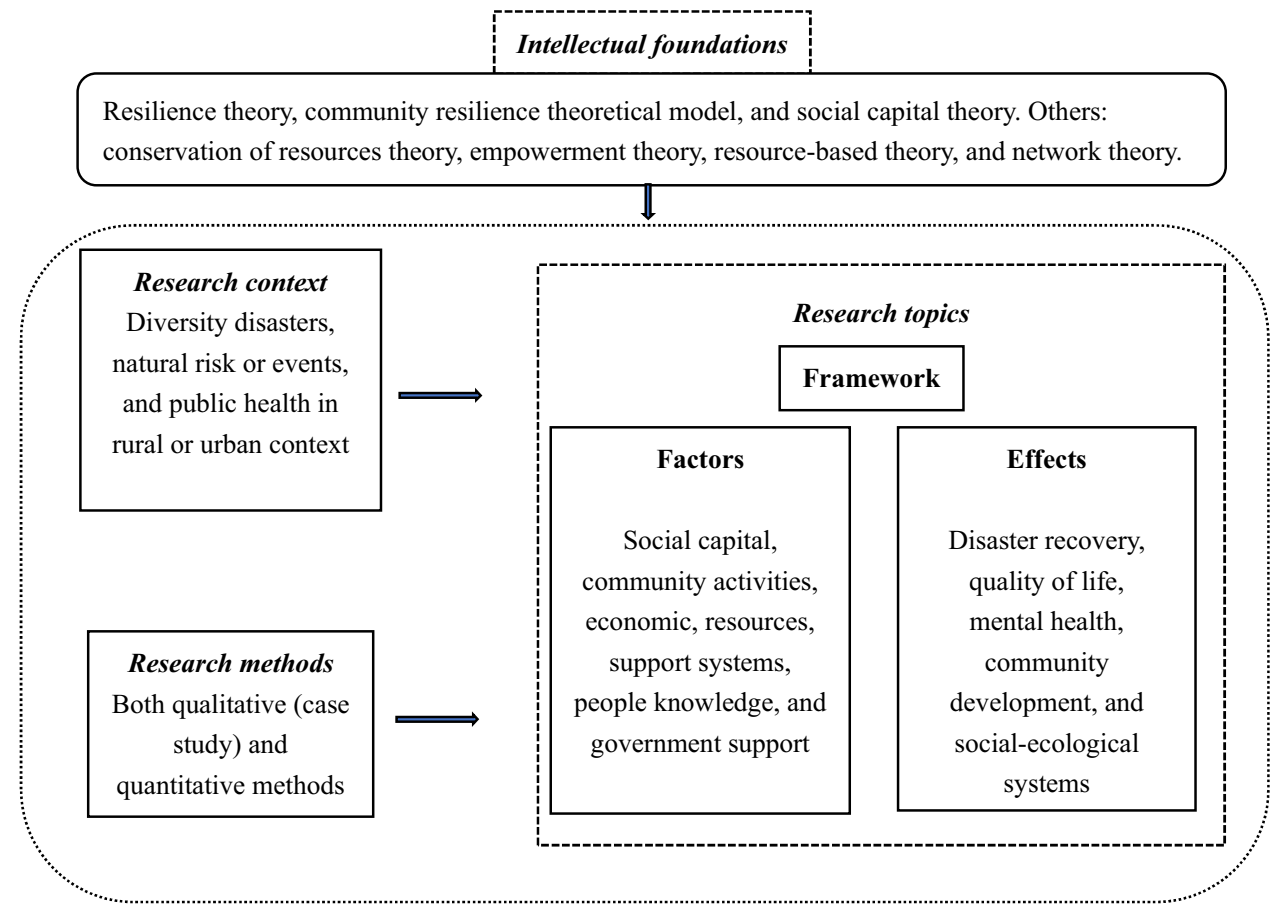

Figure 3 An overview of community resilience research in the literature. 


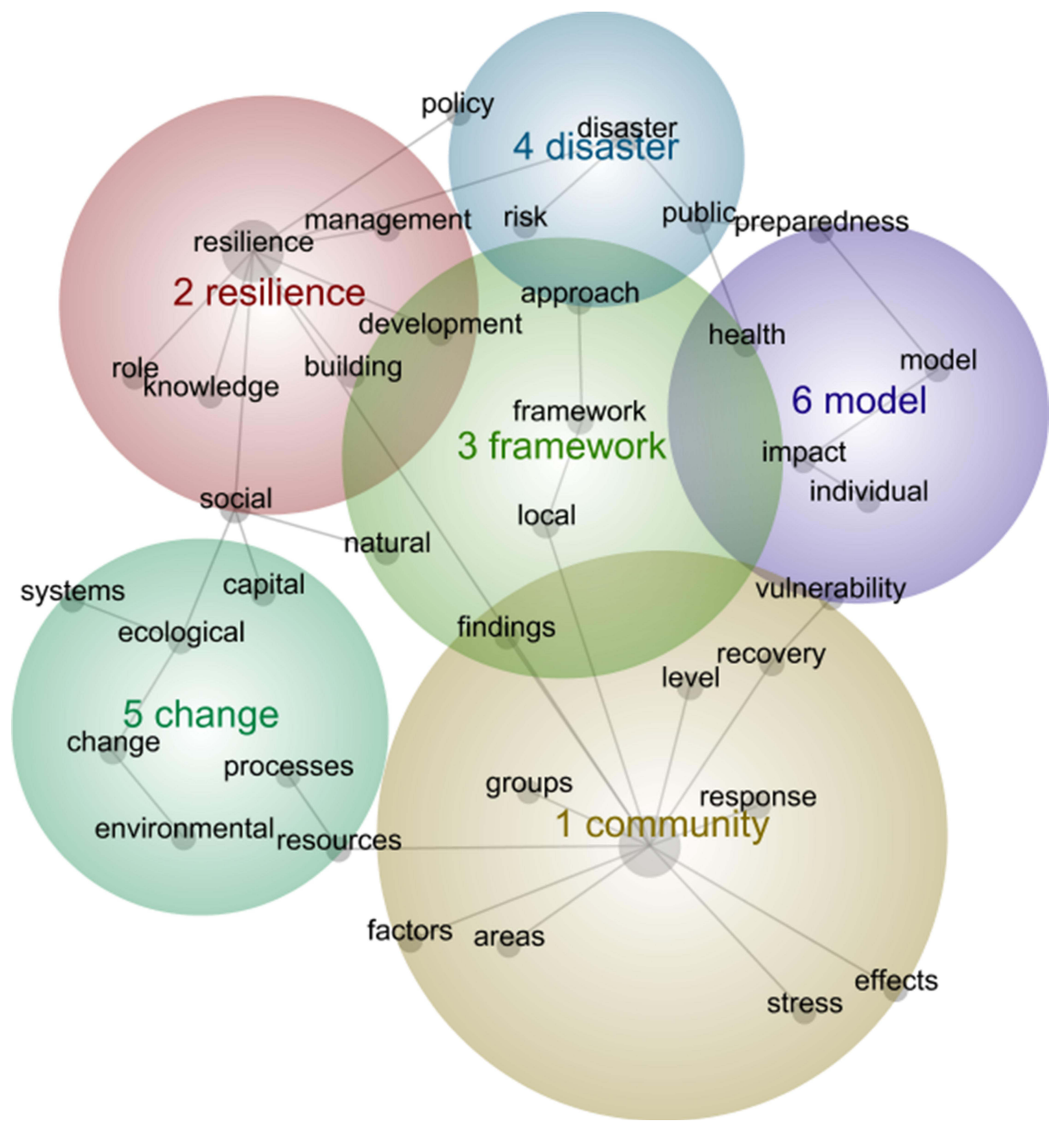

Figure 4 Theme and concept map of articles published from $200 \mathrm{I}$ to 2015 ( $\mathrm{N}=185$ articles).

$\mathrm{CR}$ is a hot topic throughout the past 20 years. The theme of capacity (ranked 5) is the most central concept connecting all the concepts in this map (after clicking the concept of capacity). The last three themes are events (ranked 6), individual (ranked 7), and government (ranked 8), with the concept of them are counted 76, 71, and 56 times respectively. After reviewing the abstract of those articles published in the last five years, we can clearly understand that almost most of the research about CR was based on the natural disasters or risk events. Additionally, people in the community and the government are the two main parts when a disaster is happening.

\section{The Analysis Across Country-Specific CR Literature}

In order to know the themes and concepts in the research site's host, we divided those 583 journal articles by country, and the top three countries with more than 50 research articles output were: USA (202 papers), Australia (54 papers), and UK (52). Furthermore, the other 65 countries, including 275 articles, were classified as one unit for analysis.

The top five themes generated from the research in the United States included "community" (893 hit times, concepts such as model, results, process, vulnerability, and different); "resilience" (889 hit times, concepts also including natural, framework, systems, planning, challenges, and key); “disaster" (389 hit times, concepts also including recovery, response, infrastructure, risk, events, and management); "change" (318 hit times, concepts also including development, local, climate, approach, public, and important); and "social" (297 hit times, concepts also including social, health, hazards, capacity, resources, and support). The text mining analysis of the Australia CR 


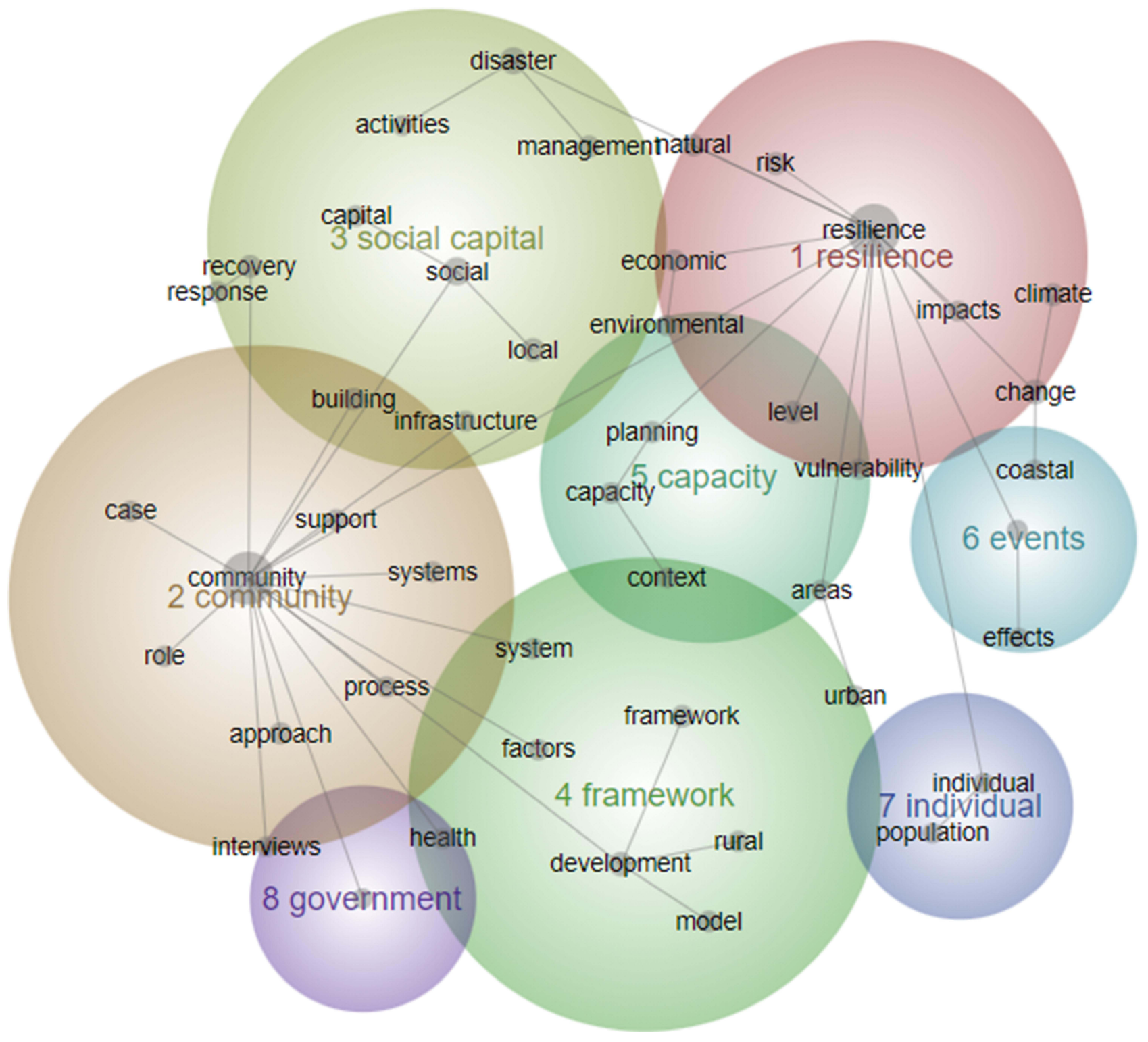

Figure 5 Theme and concept map of articles published from 2016 to 2020 ( $N=398$ articles).

research included the top five themes of "community" (254 hit times, concepts also including automated concepts of resilience, development, approach, framework, events, support, systems, and level); "disaster" (117 hit times, concepts including disaster, management, natural, response, risk, emergency, and reduction), "change" (90 hit times, concepts including change, local, climate, need, capacity, impacts and important), "social" (81 hit times, concepts also including public, policy, strategies, health, government, and responsibility); and "recovery" (29 hit times, concepts such as recovery, and related). The top five themes generated from the research in the United Kingdom included "community" (253 hit times, including automated concepts of community, resilience, local, empowerment, change, different, interviews, findings, and implications); "social" (111 hit times of social, framework, capital, building, approach, data, support, and cultural); "flood" (72 hit times of flood, risk, UK, policy, knowledge, management, and coastal); "processes" (57 hit times of processes, challenges, case, level, and organic); and "rural" (44 hit times, concepts also including role, and activities). From the literature in the other 65 countries, the top five themes included "resilience" (1383 hit times), "community" (1381 hit times), "social" (706 hit times), "disaster" (518 hit times), and "model" (146 hit times) (See Supplementary Table 1). All the five themes 
appeared on the map of three main countries, which means the $\mathrm{CR}$ research in those 65 countries followed the leading research in the three main countries (See Supplementary Table 1).

\section{Discussion and Future Research Directions}

Based on the 583 research articles about the CR from Web of Science and Scopus, concept maps were presented through Leximancer. The concept map based on the years of development stages and the $\mathrm{CR}$ research from specific-country were analyzed in our study. As presented in the results, there are some common research topics and concepts in those two perspective analyses. More importantly, there are also many different themes and concepts across two stages and cross-countries.

From the number of publications by year, the research of CR has proliferated after 2015, so we divided these 20 years of research of $\mathrm{CR}$ into two stages. It is hard to compare the results of the content analysis in the initial 15 years (2001-2015) and the last five years (2016-2020) with all data separately. However, the concepts and themes show much difference between the initial 15 years and the recent five years of research on $\mathrm{CR}$ from the concept maps. As for the initial 15 years, research on CR mainly illustrated the concept model and framework of community resilience, ${ }^{10}$ and it also showed how to respond to change through community resilience when suffering a disaster or risk. ${ }^{32}$ In the past five years, the framework of $\mathrm{CR}$ has still attracted attention from scholars. ${ }^{33}$ More importantly, it emphasized the correlation between community resilience and social capital, and it also strengthens the capacity of individuals and governments when facing events and disasters. ${ }^{34,35}$ Based on the intellectual foundations, research context, topics, and methods of CR research showing in our content analysis, follow-up research still has many directions worth exploring.

Our study detected that the themes and concepts of CR varied across countries. CR research in America has never been interrupted since 2001, and it has snowballed in the past five years. In the concept map of America, disaster is the third most prominent theme of CR research. Much research about resilience is related to the disaster, and it is related to natural and climate disasters in rural countries. ${ }^{36,37}$ As the most mature area of CR research, many researchers in America have already explored the framework, antecedent and consequent under the risk events. ${ }^{38,39}$ Research on CR in Australia appeared in 2008 and has developed rapidly in the past five years. ${ }^{40}$ Similar to the theme of research in the United States, disaster is a hot topic in the research of CR in Australia (the second most prominent theme on the map). Literature in both America and Australia emphasized the capacity and management under the risk events. ${ }^{41,42} \mathrm{CR}$ in the UK is generally considered as a process. ${ }^{43}$ Compared with the other countries, disaster in the UK was specific to flooding, meaning most $\mathrm{CR}$ research under disasters in the UK was focused on flooding. ${ }^{44-46}$ Except for New Zealand (20 papers), the literature of $\mathrm{CR}$ in each of the other 64 countries was less than 15 , with four papers on average. From the concepts in the map, "resilience" and "community" are the two most prominent themes with a series of concepts were included. There is a greater similarity with the three major countries in CR research.

There are a few limitations to this study. First, only articles published in the English language were selected. The reason is that most articles focus on CR taking place in English, and it is hard to include all related studies in other languages. However, we cannot deny that some valuable literature was published in non-English journals. Second, to ensure that all papers are related to CR, only articles with $\mathrm{CR}$ in the article title were selected, which helps us target the related papers. On the other hand, it also neglects some articles that illustrated the $\mathrm{CR}$ in the main text. Third, these 20 years of CR research were divided into two stages according to the publication amount without a better objective basis. After visualizing the title and abstract of papers about CR published in the last 20 years, most studies are review articles or case studies. It is clear that research on CR still has more work to be done in the following years. Therefore, based on the results obtained by Leximancer, we try to make recommendations and outlooks for future research on $\mathrm{CR}$.

\section{Community Resilience in Day-to-Day Lives}

Most research focused on CR under or after the circumstances of disaster or risk events. ${ }^{6}$ It is also essential to focus on a community's resilience for small shocks in dayto-day lives. Many researchers have emphasized the essential of "bounce back" after disaster or risk events to evaluate how resilient a community is and what is a critical factor of the resilience framework. ${ }^{7,15}$ However, CR should not only be able to "bounce back" after shocks and stressors but also 
allow individuals or organizations in the community to respond proactively to minor stressors and risk events in their daily life. ${ }^{48}$ As a process, CR can only play its role in a crisis if it is continuously practiced and developed in daily life. $^{49}$ Therefore, considering the unpredictability and complexities of daily life should be an essential part of future CR research.

\section{Community Resilience in Organizational Perspective}

A community can be treated as a dynamic organization. ${ }^{3}$ Connecting $\mathrm{CR}$ and organizational resilience would be meaningful for the development of $\mathrm{CR}$ research. Compared with the $\mathrm{CR}$ research, resilience in organizational and management studies has developed more maturely. Organizational resilience refers to the organizations have the capacity of the strategic awareness and operational management to deal with unexpected risk events and disruptions in advance. ${ }^{50}$ More importantly, research on organizational resilience not only handles the current crisis but also tries to achieve long-term success. ${ }^{51}$ Similar to organizational resilience, CR should not only be able to "bounce back" but also needs to be further developed for the community context. Additionally, in recent years, there has been much research on the theory of organizational resilience. ${ }^{52}$ More importantly, there is much organizational resilience research that has explored the antecedents and consequences from a quantitative perspective. ${ }^{52,53}$ So, it will be an important view for future research on resilience at the community level when dealing with risk events based on the capacity of resilience from an organizational perspective.

\section{Community Resilience Under the Different Cultural Contexts}

Cross-country comparison for CR research is essential for developing the theory and framework of future research in CR. CR research is still at the primary stage based on the results of content analysis. As we presented in the results, most CR research focused on the specific risk event in one country (concepts such as area, local, context). However, under the different cultural contexts, people have different perceptions of the community. For example, the community in the West involves both relational and regional communities. However, the community in China generally emphasizes the regional community. ${ }^{47}$ Under the different perceptions of community, $\mathrm{CR}$ in different countries has different contextual meanings. It is essential to conduct the $\mathrm{CR}$ research in regions based on a specific cultural context, but it is still meaningful to conduct the research from a comparative perspective to promote $\mathrm{CR}$ research.

\section{Conclusion}

This article presents a content analysis study using Leximancer to track the history of CR research collected on the Web of Science and Scopus database across diverse disciplines. A content analysis was conducted for the title and abstract of 583 articles by Leximancer for an overall review of research spanning 20 years. The results show that framework research of CR is a hot topic throughout the past 20 years. The main topics of the first stage (from 2001 to 2015) illustrate the concept model and framework of the CR in the context of disaster and change. Comparatively, in the second stage (from 2016 to 2020), social capital and capacity are more saliently connected with CR. Additionally, the study detected that the key issues varied across countries. Specifically, research in the US focused on the social support dynamic, while in Australia, recovery from disaster was more prominent. However, CR research from the UK focused more on resilience issues relating to floods. Overall, our findings provide a comprehensive picture of CR research covering the last 20 years and put forward thoughts and recommendations for future resilience studies considering (1) obstacles within daily life, (2) resilience set within organizational perspectives, and (3) cultural context.

\section{Data Sharing Statement}

All data that support the findings of this study are available from the corresponding author upon reasonable request.

\section{Disclosure}

The authors declare no conflict of interest.

\section{References}

1. Luthar SS. Resilience in development: a synthesis of research across five decades. In: Cicchetti D, Cohen DJ, editors. Developmental Psychopathology: Risk, Disorder, and Adaptation. John Wiley \& Sons, Inc; 2006:739-795.

2. Luthar SS, Cicchetti D. The construct of resilience: implications for interventions and social policies. Dev Psychopathol. 2000;12(4):857. doi:10.1017/S0954579400004156

3. Kirmayer LJ, Sehdev M, Whitley R, Dandeneau SF, Isaac C. Community resilience: models, metaphors and measures. Int $J$ Indig Health. 2009;5(1):62-117. 
4. Lengnick-Hall CA, Beck TE, Lengnick-Hall ML. Developing a capacity for organizational resilience through strategic human resource management. Hum Resour Manag Rev. 2011;21 (3):243-255.

5. Walton AM, McCrea R, Leonard R, Williams R. Resilience in a changing community landscape of coal seam gas: Chinchilla in Southern Queensland. J Economic Soc Policy. 2013;15(3):0_1,0_2,1-23.

6. Tobin GA, Whiteford LM. Community resilience and volcano hazard: the eruption of Tungurahua and evacuation of the Faldas in Ecuador. Disasters. 2002;26(1):28-48. doi:10.1111/1467-7717.00189

7. Berkes F, Ross H. Community resilience: toward an integrated approach. Soc Nat Resour. 2013;26(1):5-20. doi:10.1080/ 08941920.2012 .736605

8. Quinn T, Adger WN, Butler C, Walker-Springett K. Community resilience and well-being: an exploration of relationality and belonging after disasters. Ann Am Assoc Geogr. 2020;111(2):577-590.

9. Norris FH, Stevens SP, Pfefferbaum B, Wyche KF, Pfefferbaum RL. Community resilience as a metaphor, theory, set of capacities, and strategy for disaster readiness. Am J Community Psychol. 2008;41(12):127-150. doi:10.1007/s10464-007-9156-6

10. Ainuddin S, Routray JK. Community resilience framework for an earthquake prone area in Baluchistan. Int $J$ Disaster Risk Reduct. 2012;2:25-36. doi:10.1016/j.ijdrr.2012.07.003

11. Revell P, Henderson C. Operationalising a framework for understanding community resilience in Europe. Reg Environ Change. 2019;19(4):967-979. doi:10.1007/s10113-018-1390-y

12. Koliou M, van de Lindt JW, McAllister TP, Ellingwood BR, Dillard M, Cutler H. State of the research in community resilience progress and challenges. Sustain. 2020;5(3):131-151.

13. Nietzsche F. The Twilight of the Idols. Jovian Press; 2018.

14. Smith JM, Maynard SJ. The Theory of Evolution. Cambridge University Press; 1993.

15. Holling CS. Resilience and stability of ecological systems. Annu Rev Ecol Evol Syst. 1973;4(1):1-23. doi:10.1146/annurev.es.04.1101 73.000245

16. Keck M, Sakdapolrak P. What is social resilience? Lessons learned and ways forward. Erdkunde. 2013;67:5-18. doi:10.3112/erdkunde. 2013.01.02

17. Buikstra E, Ross H, King CA, et al. The components of resiliencePerceptions of an Australian rural community. J Community Psychol. 2010;38(8):975-991. doi:10.1002/jcop.20409

18. Barzilai G. Communities and Law: Politics and Cultures of Legal Identities. University of Michigan Press; 2010.

19. Dvarskas A. Mapping ecosystem services supply chains for coastal Long Island communities: implications for resilience planning. Ecosyst Serv. 2018;30:14-26. doi:10.1016/j.ecoser.2018.01.008

20. Kulig JC. Community resiliency: the potential for community health nursing theory development. Public Health Nurs. 2000;17 (5):374-385. doi:10.1046/j.1525-1446.2000.00374.x

21. Brown DD, Kulig JC. The concepts of resiliency: theoretical lessons from community research. Health Can Soc. 1996;1(4):29-50.

22. House W. Presidential Policy Directive/PPD 21-Critical Infrastructure Security and Resilience. Washington, DC; 2013.

23. Magis K. Community resilience: an indicator of social sustainability. Soc Nat Resour. 2010;23(5):401-416. doi:10.1080/0894192090330 5674

24. Bhandari S, Alonge O. Measuring the resilience of health systems in low- and middle-income countries: a focus on community resilience. Health Res Policy Syst. 2020;18:1. doi:10.1186/s12 961-020-00594-w

25. McCrea R, Walton A, Leonard R. A conceptual framework for investigating community wellbeing and resilience. Rural Soc. 2015;23(3):270-282. doi:10.1080/10371656.2014.11082070

26. McCrea R, Walton A, Leonard R. Developing a model of community wellbeing and resilience in response to change. Soc Indic Res. 2016;129(1):195-214. doi:10.1007/s11205-015-1099-y
27. Pfefferbaum RL, Pfefferbaum B, Nitiema P, Houston JB, Van Horn RL. Assessing community resilience: an application of the expanded CART survey instrument with affiliated volunteer responders. Am Behav Sci. 2015;59(2):181-199. doi:10.1177/00027 64214550295

28. Kulig JC, Edge DS, Townshend I, Lightfoot N, Reimer W. Community resiliency: emerging theoretical insights. $J$ Community Psychol. 2013;41(6):758-775. doi:10.1002/jcop.21569

29. Vaneeckhaute LE, Vanwing T, Jacquet W, Abelshausen B, Meurs P. Community resilience 2.0: toward a comprehensive conception of community-level resilience. Community Dev. 2017;48(5):735-751. doi:10.1080/15575330.2017.1369443

30. Smith AE, Humphreys MS. Evaluation of unsupervised semantic mapping of natural language with Leximancer concept mapping. Behav Res Methods. 2006;38(2):262-279. doi:10.3758/BF031 92778

31. Bell E, Blashki G. A method for assessing community flood management knowledge for vulnerable groups: australia's 2010-2011 floods. Community Dev J. 2014;49(1):85-110. doi:10.1093/cdj/bst002

32. Steiner A, Markantoni M. Unpacking community resilience through capacity for change. Community Dev J. 2014;49(3):407-425. doi:10. 1093/cdj/bst042

33. Cafer A, Green J, Goreham G. A community resilience framework for community development practitioners building equity and adaptive capacity. Community Dev. 2019;50(2):201-216. doi:10.1080/ 15575330.2019.1575442

34. Revell P, Dinnie E. Community resilience and narratives of community empowerment in Scotland. Community Dev J. 2020;55(2):2 18-236. doi:10.1093/cdj/bsy038

35. Vaneeckhaute LE, Vanwing T, Meurs P, Abelshausen B, Jacquet W. Community capitals of a Paramaca Maroon village in pictures: a photovoice study on community resilience in the context of large-scale gold mining. Community Dev J. 2019;54(2):233-253. doi: $10.1093 / \mathrm{cdj} / \mathrm{bsx} 036$

36. Perz SG, Cabrera L, Carvalho LA, Castillo J, Barnes G. Global economic integration and local community resilience: road paving and rural demographic change in the Southwestern Amazon. Rural Sociol. 2010;75(2):300-325. doi:10.1111/j.1549-0831.2009.00008.x

37. Allen M, Gillespie-Marthaler L, Abkowitz M, Camp J. Evaluating flood resilience in rural communities: a case-based assessment of Dyer County, Tennessee. Nat Hazards. 2020;101(1):173-194. doi:10. 1007/s11069-020-03868-2

38. Qiang Y, Huang QX, Xu JW. Observing community resilience from space: using nighttime lights to model economic disturbance and recovery pattern in natural disaster. Sustain Cities Soc. 2020;57:11. doi:10.1016/j.scs.2020.102115

39. Zhang XA, Shay R. An examination of antecedents to perceived community resilience in disaster postcrisis communication. $J$ Mass Commun Q. 2019;96(1):264-287.

40. King CA. Community resilience and contemporary agri-ecological systems: reconnecting people and food, and people with people. Syst Res Behav Sci. 2008;25(1):111-124. doi:10.1002/sres.854

41. Stark A, Taylor M. Citizen participation, community resilience and crisis-management policy. Aust J Polit Sci. 2014;49(2):300-315. doi:10.1080/10361146.2014.899966

42. Singh-Peterson L, Underhill SJR. A multi-scalar, mixed methods framework for assessing rural communities' capacity for resilience, adaptation, and transformation. Community Dev. 2017;48 (1):124-140. doi:10.1080/15575330.2016.1250103

43. Wilson GA. Community resilience and social memory. Environ Values. 2015;24(2):227-257. doi:10.3197/096327114X13947900182 157

44. Soetanto R, Mullins A, Achour N. The perceptions of social responsibility for community resilience to flooding: the impact of past experience, age, gender and ethnicity. Nat Hazards. 2017;86 (3):1105-1126. doi:10.1007/s11069-016-2732-z 
45. McEwen L, Garde-Hansen J, Holmes A, Jones O, Krause F. Sustainable flood memories, lay knowledges and the development of community resilience to future flood risk. Trans Inst Br Geogr. 2017;42(1):14-28. doi:10.1111/tran.12149

46. Ntontis E, Drury J, Amlot R, Rubin GJ, Williams R. Endurance or decline of emergent groups following a flood disaster: implications for community resilience. Int J Disaster Risk Reduct. 2020;45:9. doi:10.1016/j.ijdrr.2020.101493

47. Audin J, Throssell K. Governing through the neighbourhood community (shequ) in China. Rev Fr Sci Polit. 2015;65(1):85-110. doi:10.3917/rfsp.651.0085

48. Haggard R, Cafer A, Green J. Community resilience: a meta-study of international development rhetoric in emerging economies. Community Dev. 2019;50(2):160-180. doi:10.1080/15575330.2019.1574851

49. Vertigans S, Gibson N. Resilience and social cohesion through the lens of residents in a Kenyan informal settlement. Community Dev J. 2019;55(4):624-644.
50. Annarelli A, Nonino F. Strategic and operational management of organizational resilience: current state of research and future directions. Omega. 2016;62:1-18. doi:10.1016/j.omega.2015.08. 004

51. Andersson T, Caker M, Tengblad S, Wickelgren M. Building traits for organizational resilience through balancing organizational structures. Scand J Manag. 2019;35(1):36-45. doi:10.1016/j.scaman. 2019.01.001

52. Mousa M, Abdelgaffar HA, Chaouali W, Aboramadan M. Organizational learning, organizational resilience and the mediating role of multi-stakeholder networks A study of Egyptian academics. J Workplace Learn. 2020;32(3):161-181. doi:10.1108/JWL-05-20190057

53. Herbane B. Locational contiguity and business continuity: perceived organizational resilience of small- and medium-sized enterprises in U.K. business parks. SAGE Open. 2020;10(2):2158244020927417. doi: $10.1177 / 2158244020927417$

\section{Publish your work in this journal}

Psychology Research and Behavior Management is an international, peer-reviewed, open access journal focusing on the science of psychology and its application in behavior management to develop improved outcomes in the clinical, educational, sports and business arenas. Specific topics covered in the journal include: Neuroscience, memory and decision making; Behavior modification and management; Clinical applications; Business and sports performance management; Social and developmental studies; Animal studies. The manuscript management system is completely online and includes a very quick and fair peer-review system, which is all easy to use. Visit http://www. dovepress.com/testimonials.php to read real quotes from published authors. 